\title{
I I
}

\section{Evidence with insight: what models contribute to EU research}

\author{
GERALD SCHNEIDER, BERNARD STEUNENBERG AND \\ MIKA WIDGRÉN
}

\section{I.I INTRODUCTION}

The Treaties of Maastrict, Amsterdam, and Nice are milestones of European integration. In each case, the negotiation and ratification processes attracted widespread media and popular attention. More recently, the Treaty Establishing a Constitution for Europe also drew sustained interest from broad sectors of European society until it failed ratification in several member states during 2005. Academics are drawn to stirring events just as the press and public are, and thus many political scientists have written engagingly about the 'grand bargains' embodied in the successive EU treaties (e.g. Moravcsik I998).

Day to day, however, the business of the EU does not make front-page headlines. Like any government, the EU spends most of its time deciding routine matters, such as the wording of health warnings on tobacco products or the funding of student exchanges in Europe. Indeed, both tobacco label and student exchange decisions appear in the data set used in this book. The EU's own organs decide these issues-the Commission, the Council of Ministers, and the European Parliament (EP). Mid-level civil servants and ordinary Members of the European Parliament (MEPs) may play critical roles. Prime ministers and chancellors, who loom so large in the grand bargains, do not.

In this volume, we have directed our energies toward the explanation of every-day EU decisions. We make no apology for doing so. Although some legislative acts are merely technical correctives or minor bureaucratic rule-making, the great majority of the decisions examined here

We would like to thank Christopher Achen, Frans Stokman, Daniela M. Bailer-Jones, Antoaneta Dimitrova, the reviewers and editors of this book for their helpful comments and suggestions. The title is a paraphrase of Singer (I969). 
affect the lives of many Europeans. The daily multiplication of such decisions, cumulating over many years, has altered Europe dramatically and irrevocably, in ways visible to the entire world.

Thus understanding the quotidien political battles of the EU is not of minor concern. To the contrary, the relentless march of daily decisionmaking has at least as much importance and deserves every bit as much attention as the sporadic grand bargains that dot recent European history. Both are critical to understanding why the EU has had the impact it has had, and why it is among the world's most effective supra-national political organisations. But only the grand bargains have enjoyed extensive discussion. Hence the focus of this book: how can we explain every-day decisions in the European Union?

The approach we have taken derives from rational choice theory, simply because the recent upsurge in game-theoretic models of EU decision-making has added so dramatically to our understanding. Yet the accomplishments of the past few years have been primarily conceptual: we learned a great deal about the internal coherence of our ideas and about the logical implications of our explanations. Contradictions in our previous informal explanations were discovered, and our attention was directed to seemingly minor aspects of EU policy-making that turned out to have large, previously unnoticed theoretical consequences. However, until the publication of this volume and an accompanying special issue of European Union Politics, we did not know nearly as much about how these competing approaches fare in explaining and predicting a broad set of decision outcomes. The dual purpose of this volume, therefore, has been to set out the wide variety of existing rational choice models, and then to explore how well they predict actual EU legislative outcomes.

The models in this volume fall into three main sets. The first group, the procedural models, emphasise the decision-making rules and formal procedures that constrain the actors. The sequence of moves by the various actors within those rules is taken to be the crucial element of EU decision-making. These models use the formal legislative rules in order to describe the game form, that is, the definition of players, their decision-making rights and the sequence in which they can make their choices. Of course, some aspects of EU decision-making are not formalised and thus are subject to alternate interpretations. Is the Commission a gatekeeper, in the sense that it can ignore requests by the Council and EP to initiate legislative proposals? Does the Council or Parliament move first in drafting a compromise proposal under the co-decision procedure? Scholars disagree. Most models developed in this approach therefore 
combine the formal rules with an interpretation of the informal norms, as Chapter 3 demonstrated. The procedural models then use the Nash equilibrium or its refinements for identifying and predicting outcomes.

The second set of models in this book stress the informal bargaining and negotiations that occur before the formal decision-making takes place. We label this category bargaining models. The proponents of this theoretical tradition do not assume the institutional setting away. They maintain that formal rules and procedures create settings for informal negotiations, as well as fallback options when negotiations fail. The legal rules determine which actors are included in the negotiation process and how much weight is given to their positions, but they are not the actual decision mechanism themselves. Bargaining is the central decision-making process, not voting.

The bargaining models in the present volume assume that only actors with formal voting power matter. National and cross-national interest groups may have shaped the positions adopted by the member states, for example, but that activity is prior to the starting point of the data set under study. Thus the bargaining models in this book generally assume that the weights of actors in the informal negotiations primarily depend on their formal voting power. Hence they take the Shapley Shubik Index (SSI) as a good estimate of these weights. Some of the bargaining models in this book assume that the grand coalition of all actors forms. Others investigate bilateral deals between actors, which have positive or negative externalities for other actors, and still others investigate noncooperative bargaining solutions. The cooperative solutions base their predictions on the Nash bargaining solution.

The third group of models attempts to combine a partial characterisation of an extensive form bargaining game with the procedural voting game played according to legal rules. We call these mixed models. These approaches presume that pre-play agreements can be interpreted as a first step in the decision-making process. A compromise, for instance, might amount to an exchange of votes or to an agreement on the relative importance of different conflictual issues in one legislative proposal. However, formal rules and procedures determine the solution of remaining controversies. For the latter, non-cooperative equilibrium concepts are normally applied, but within the restricted set of feasible outcomes of the pre-play negotiations.

Most of the models presented here have been developed in other contexts. The procedural models, for instance, have been employed mainly to explain how rules structure legislative interactions within the 
US Congress. Cooperative bargaining models enjoy a rich intellectual heritage starting with the seminal contributions of Edgeworth and Nash. Bargaining models have been used extensively for political forecasting and strategic intervention (Bueno de Mesquita 2002; Stokman et al 2000). In this book, the models have been adapted to the context of the European Union. Each model and the mechanisms behind its predictions are illustrated with case studies which help validate the assumptions, but also show where potential weaknesses lie.

The last and perhaps most important feature of this volume is that the different models are tested empirically against baseline models and against each other. This collaborative research effort is to our knowledge the largest attempt ever undertaken to empirically evaluate competing decision-making models. Until now, due to the absence of a common data set that could be used to assess the predictive power of alternative models, it has been impossible to compare different explanations of EU policy-making (Gabel et al 2002). Critics could always attribute the failures of their favourite models to the differences in case selection strategies. By contrast, our research design focuses all models on a common data set. This research strategy is relatively new to legislative studies, and combined with the size of the decision sample, it provides a unique opportunity to assess closely the empirical validity of different explanatory models.

In the remainder of this chapter, we will summarise which models predict best and discuss why the performance of the models differs. Then, because the theoretical and empirical findings presented in this book open avenues to improving both the models and the strategies for testing them, we will conclude by attempting to foresee what future research on this topic might accomplish.

\section{I.2 THE MAIN FINDINGS AND THEIR IMPLICATIONS}

The theoretical debate on European integration has long focused on unwieldy questions with either unknowable or obvious answers: what is the true nature of regional collaboration? Among regional collaborations, is the European Union sui generis or can it be compared to other political entities? Questions of this kind are definitional or at best descriptive; they are not researchable in any deeper sense.

Since the I990s, however, we have witnessed an increasing number of studies that present testable hypotheses. The neo-institutionalist approach has been particularly instrumental in moving the field towards 
'normal science' (Aspinwall and Schneider 2000; Dowding 2000). The theoretical and empirical research reported in this volume aims to push these discussions one step further.

The first area in which this book attempts a contribution is the procedural theory of legislative choice. While examinations of the choices made by the European Parliament or other EU institutions were largely behaviouralist until the mid-I990s, the simultaneous publication of two examinations of the cooperation procedure gave impetus to the rigorous formal study of legislative rules (Steunenberg I994a; Tsebelis 1994). As noted above, one disturbing aspect of these studies has been the frequent disagreement among researchers about the 'game' institutional actors are supposed to be playing. The first dispute focused on the question of whether or not the institutional changes of the r $980 \mathrm{os}$ empowered the European Parliament.

A second debate arose in the r990s when the European Union introduced the co-decision procedure. Tsebelis (I997) claimed that this constitutional change weakened rather than strengthened the legislature, while Crombez (200I) and Steunenberg (1997; 2002a) attributed more power to the Parliament. These divergent theoretical claims can now be confronted with empirical results. As indicated by Steunenberg and Selck in Chapter 3, Parliament appears, next to the Council, to be a strong and important legislative actor under the co-decision procedure. By making the initial proposal to the intergovernmental body, Parliament in their view has a first-move advantage, which forms the starting point for further negotiations. This suggests that Parliament may not have lost its 'conditional agenda-setting power', as Tsebelis claimed it had. On the contrary, it can engage in direct negotiations with the Council, a power it did not have under the cooperation procedure. This result, which is supported by other empirical work (Kasack 2004; König and Pöter 200I; Selck and Steunenberg 2004), may indicate that the current co-decision procedure has indeed strengthened Parliament's power.

The second contribution of this volume to legislative analysis lies in bargaining interpretations of EU policy-making. As a broad conclusion, the empirical analyses in Chapter ro suggest that bargaining models perform better than procedural models, and that among the models that incorporate bargaining, pure bargaining models based on cooperative game theory do better than those that mix procedural and bargaining aspects. Put another way, at this stage of our understanding, pure bargaining models predict best as a class, while pure legalist models perform 
worst. The more mixed models include procedural aspects, the worse they do.

This set of findings is supported by parallel studies, where other game theory concepts interpretable as bargaining outcomes also performed quite well in explaining outcomes of EU decision-making. In a study on EU budget allocations, Baldwin et al (200I) find that a straightforward cooperative solution concept like the Shapley Shubik Index explains receipts far more accurately than does the income level of a country or the share of agriculture in its GDP, which are the two main ingredients of budget transfers. More recently, Kauppi and Widgrén (2004) reached the same conclusion using a considerably enlarged data set on EU budget receipts between I976 and 200I. The Shapley Shubik Index was not, however, able to capture all variation in budget transfers. The explanatory power of this cooperative solution improved considerably when $a$ priori coalitions among member states were allowed. Surprisingly, the best performing coalition structures were relatively stable over time, consisting of the same member states. This confirms our own finding that cooperative models need to take the detailed structure of actors' preferences into account and to use the Shapley Shubik values as important influences on the outcome rather than as final predictions. That is what the models in this book do.

Another implication of the bargaining perspective follows as well. If the final vote is less important than the haggling taking place before it, we should question the relevance and reliability of the numerous studies that try to uncover the issue dimensions in the Council of Ministers or the European Parliament using data on roll call voting (Matilla and Lane 200I; Carruba et al 2004). Valuable as those studies have been, they may be improved by further work that takes voting positions as strategic choices rather than the original raw preferences, as bargaining theory suggests.

Why is the bargaining perspective more successful in predicting outcomes than other models? Part of the reason is that unanimity appears to be a strong norm in EU legislation, even when qualified majority voting (QMV) is allowed. EU personnel believe that consensus is right decision mode. This suggests that legal characteristics of the decision-making procedure, such as the voting rule or the order in which political actors may propose legislation or cast their vote, shape the final outcomes less dramatically than procedural models imagine.

Procedural models probably suffer most from their implicit assumption that day-to-day decision-making consists of thousands of unrelated 
single-shot events, so that political actors ought to maximise their selfinterest on every one. However, even when the rules permit it, exploiting the weak is not regarded as being an appropriate way of making decisions. Unilateral aggressive moves, however 'rational' from the singleplay perspective of most procedural models, may lead in practice to unfavourable responses by other players, which both endanger the proper functioning of the institution and damage the potential exploiter as well. This perspective helps explain why, among the various models discussed in this volume, those using the procedural variation in legal contexts to predict outcomes frequently misfire. As our collective research effort indicates, adopting EU legislation by unanimity, whenever possible, is a shared norm no matter what the legal context, and that norm seems to overpower the legal rules.

In addition, the alignments of EU actors are often highly case specific. A single dimension statistically accounts for only one third of the variance of all actor positions (Thomson et al 2004; Zimmer et al 2005). In policy areas without stable patterns of coalition formation, actors can be confident that every other actor will need their help at some future date. Thus the concessions they make to actors who have high interests in the issues currently being discussed will be compensated in future situations when their own interests matter more. Such reciprocal, non-negotiated exchanges are highly important in generating unanimously supported solutions, even when a qualified majority is legally able to impose its will (Stokman 2004; 2005). All these conditions strongly facilitate the universally inclusive, compromise mode of decision-making that predicts outcomes best.

Under these conditions, and assuming that actors have quadratic loss functions on the issue continua (implying risk aversion), Achen showed in Chapter 4 that the average of the policy positions, weighted by the product of each actor's power and salience, is a first-order approximation of the cooperative Nash bargain solution. It is this solution, denoted the compromise model, that gives the best predictions of all models. This model implies that powerful actors who attach most salience to the issues receive the largest concessions from the other negotiators. However, all actors are conciliated to some degree even if they could legally be ignored.

Another variation of the bargaining model stresses the importance of positional exchanges. The position exchange model investigates whether explicitly negotiated bilateral deals between actors, involving issue linkages, can improve upon the predictive accuracy of the Nash bargaining 
solution. Such bilateral deals can contribute to consensus-building when the resulting shifts in the outcomes have positive externalities for the other actors, i.e., when the outcomes shift in the direction of the preferred positions of third actors, not involved in the exchanges. When the decision outcomes move away from the preferred positions of actors not directly involved in the exchange, negative externalities are created. When this is the case, such bilateral deals are likely to hinder consensus-building.

The distribution of positions and saliencies on the controversial issues within the 66 European Commission proposals studied here is such that the negative externalities of the bilateral exchanges predicted by the position exchange model are about twice as high as the positive externalities. This shows that purely bilateral exchanges in these proposals tend not to contribute to consensus-building. Arregui, Stokman and Thomson (Chaper 5) see this as the most important reason why the exchange model did not improve upon the accuracy of the compromise model, whereas it did so in a test with a smaller data set (Bueno de Mesquita and Stokman 1994) and in other applications.

If common interests and reciprocal exchanges between permanently changing coalitions indeed prevail, then negotiation strategies backed by power dominance or implicit threats will be uncommon in EU decision-making. Hence we would expect the non-cooperative bargaining model developed by Bueno de Mesquita (the challenge model presented in Chapter 5 of this book) to predict only modestly well. Indeed, in our study the challenge model performs only a bit better than the procedural models and much less well than the compromise and exchange models.

This finding differs from that of Bueno de Mesquita and Stokman (1994), who examined a small data set on decision-making in the Council of Ministers. In that study, Bueno de Mesquita's model performed as well or even a bit better than the compromise and exchange models, though the differences were not statistically significant. It now appears from our larger sample that, if our data set is indicative, the challenge model was favoured by statistical good fortune in the earlier, smaller trial.

These findings do not imply that Bueno de Mesquita's threat mechanisms are unimportant. On the contrary, consensus on the prevailing common interests will not survive long if it cannot be connected with a sanctioning mechanism that ensures the enforcement of compromises. Formal rules provide safeguards to actors in case fundamental problems 
arise or some actors misbehave. However, regular use of implicit threats probably does not account for much EU decision-making. The more often member states or other EU actors have to resort to threats, the more fragile the consensus norm will become. In a private relationship, referring a conflict to the court to enforce a contract usually results in the ending of that relationship. Similarly, frequent use of the letter of the law decision by decision is likely to undermine the perception of common interests (Stokman 2004; 2005). It is this gap between daily life in the EU and the assumptions of Bueno de Mesquita's model that may account for the relative lack of success of his model in our data.

If self-interested exploitation of procedural rules undermines the consensus norm, and if unanimous decisions are desirable, partial agreements supported by majorities only will be avoided. This perspective helps explain why a Nash bargaining solution or compromise model applied solely within minimal winning coalitions encounters prediction errors. Thus in the model presented in Chapter 7, minimal winning coalitions are evaluated against each other on the basis of the amount of conflict expected within them. Conflict is assumed to depend either on the spread of the initial positions of the actors within the coalition, or on how evenly losses are distributed among the actors in the coalition. The less conflictual coalitions form, and the compromise model determines payoffs within them. The model is intuitively appealing and its predictive performance places it among the better models, but nonetheless it predicts less well on average than the compromise model, which uses the same payoff formula but applies it to the grand coalition involving all actors.

Two other mixed models also appeared in this book. The procedural exchange model, presented in Chapter 8, assumes that actors first exchange power resources, giving extra weight to issues that are of high interest to them at the expense of issues in which they are less interested. Subsequently, decisions are taken according to the relevant procedural rule, taking into account the redistribution of actors' power during the prior exchange process. The second such model, the conditional procedural model presented in Chapter 9, assumes that complexity increases quickly with the number of controversial issues in a Commission proposal. The model therefore assumes that all controversial issues are first reduced to one overall dimension of conflict. Subsequently, the relevant procedural rule is applied to determine the outcome on that integrated dimension. Both these models generate predictions with a high average error. 


\section{I.3 THE LIMITS OF PREDICTIVE POWER AND THE NEED FOR ADDITIONAL DATA}

During the past few years, discussion of the linkage between theoretical and empirical work has intensified in political science (e.g. Morton I999), economics (e.g. Stigum I990), and sociology (e.g. Opp I990), and this debate has already led to discussion on the appropriate tools to test models (e.g. Signorino 1999; Clarke 2003). Sophistication about testing is important. For example, the different chapters in this volume show that naïve models such as the mean of actor preferences often do better than those with a solid theoretical foundation. The gametheoretical work on the European Union, it should be pointed out, is not alone in this regard. If prediction is the only yardstick for the evaluation of a social-scientific explanation, 'role playing', for instance, may produce more accurate forecasts than sophisticated theoretical models (De Gooijer 2002; Erev et al 2002).

Ad hoc predictions and 'rules of thumb' have limited explanatory value. Meteorologists are not satisfied theoretically by 'the weather of tomorrow will be like the weather of today', even though that statement has a high likelihood of forecasting correctly. Similarly, the median and the mean might predict EU decisions reasonably well, but they give no insight into the underlying causal mechanisms. Why did the decision end up in the middle of actor preferences? Only theoretically informed models that model individual human choices-micro-foundationscan answer that question. Prediction and explanation are not the same thing.

To paraphrase Singer (I 969), we need evidence with insight. Neglecting one aspect at the expense of another leads to either anaemic 'model platonism' (Albert 1965) or to barefoot empiricism ${ }^{\mathrm{I}}$ (see also Morgan and Morrison 1999). As Achen noted in Chapter ro, however, the challenge in studying the EU is that at present, our insightful models do only modestly well with the evidence, while those that track the data, like the mean, median, and even the compromise model, provide only limited insight into the causal processes. Thus much remains to be done.

To do better in future, more attention will need to be paid to measurement issues. There is a subtle reciprocal relationship between collection of the data needed for modelling and construction of models to fit those

${ }^{\text {I }}$ Philosophers of science disagree over the place of models in the scientific process. For a recent discussion see Bailer-Jones (2003). 
data. A fascinating case study by Van den Bogaard (I999) details how choices about model specification and data usage were intertwined in setting up the Tinbergen model in the I930s, which became the central modelling device of the Dutch Central Planning Bureau 20 years later. She writes that this influential macro econometric model 'was used as an aid in decisions concerning measurement and was itself used as a reason to develop the measurement system' (Van den Bogaard 1999: 308-309).

Similarly, we need to address both the implications of the empirical results for the theoretical models and the implications of the way in which we measured crucial concepts for the performance of the models. Some models in this book required data that were difficult to collect because the expert practitioners used as informants could not easily recognise the concepts at issue. An issue for future research is whether the data collection procedures or those models need to be rethought.

Another critical measurement issue is the construct validity of the variables we measured. This technical term stands for the extent to which key factors are measured adequately. The research team collectively considered various options for measurement and data collection, aiming at the best data attainable within budget constraints (see Chapter 2 for a more detailed discussion). Inevitably, tradeoffs were made. Data sets are imperfect, and this one is no exception. For example, we asked the expert observers to assign interval scale scores to ordinal data, even when we suspected that other policy options unknown to us were probably discussed by the actors involved but omitted from our ordinal rankings. Some members of the group were concerned that applying quadratic loss computations to the resulting ordinal and dichotomous measures, including multi-dimensional versions of those versions, as we did in Chapter Io, might have worse consequences than just the usual minor difficulties of any approximation. They felt that doing so might violate the basic assumptions of the spatial theory of voting (Enelow and Hinich 1984; Hinich and Munger 1997), or might inappropriately distort the rankings of model performance. They preferred other preference measures developed within the social choice literature, but not yet applied to the context of European Union decision-making. ${ }^{2}$ Other members of the group disagreed.

2 See, for instance, Holler's (1994) extension of a model proposed by Steunenberg (I994b) on regulatory policy-making, and Van Hees and Steunenberg's (2000) model of how courts rule. 
To flag such issues, authors of some chapters have appropriately pointed out these and other possible weakness of the data set, which should be taken into account in further research, as Bueno de Mesquita (2004) discusses in detail. In particular, it would be very helpful to estimate accurately the full number of options that were available to the stakeholders. To do so, future researchers will undoubtedly supplement the interview material with the protocols from the Council and other decision-making bodies.

Finally, we note that we analysed 'successful' decisions in this study. The error reported in the different chapters concerns the difference between the outcome predicted by some model and the actual outcome. Only cases for which a final proposal was made are included. This means that the empirical analysis does not account for the withdrawal of a proposal by the Commission, or cases that were not decided within the timeframe used for the data collection. The main finding of consensual decision-making among the member states in the Council and between the Council, Commission and Parliament may have been affected by this choice. Further analysis of the cases of non-decision-making, in which the Commission withdraws a proposal or the member states postpone further discussion, may help in understanding the conditions under which consensual decision-making in the Union is effective.

\section{I.4 THEORETICAL ISSUES FOR FUTURE RESEARCH}

What are the ways ahead for theory development? The findings presented in this volume show some ways to improve future EU research based on the experiences and findings from the current project.

First, we assumed that the Commission and the Parliament can be represented as unitary actors. ${ }^{3}$ We all know that the Commission consists of different Commissioners who are responsible for distinctive EU policies and bring their own ideology and commitments to the cabinet meetings in Brussels. Yet a strong norm of unanimity operates within the Commission. Parliament, too, consists of different national and

\footnotetext{
3 In fact, we asked our experts whether different actors within these supranational institutions played a role. Our experts, however, always believed that the Council of Minister's needs to be disaggregated, but not the Commission and the Parliament. One could easily accuse our contributions to be biased in favour of the member states. We believe, however, rather that most of the current research underestimates the importance of the Council and concentrates on actors that have often only a marginal influence on the decision-making processes.
} 
party groups, yet they do not act cohesively on all legislative proposals. Moreover, the parliamentary discussions are channelled through the standing committees and their individual rapporteurs, another source of diversity. Further research is needed to analyse the aggregation of these preferences into the 'official' or group preference, and to determine how consequential our unitary actor assumption is for model predictions.

This view of EU policy-making has implications for the analysis of legislative decision-making. The preparatory process, during which working groups of representatives from the different national ministries and permanent representations are active, might thus be much more important for the final result than the more formalised legislative negotiations on which some of the models in this volume focus. The work of these diplomatic 'sherpas' often leads to proposals that are passed without further discussion within the Council (see Beyers and Dierickx 1997). At what level-the working group, committee of permanent representatives (COREPER), or ministerial—are the early-stage controversies resolved?

The growing importance of the Parliament as a co-legislator has also led to the development of informal structures to accommodate them early on. Starting with the conciliation committee meetings, in which the Council and Parliament formally negotiate on controversial issues, the Commission has initiated informal meetings with representatives from the Council and Parliament to discuss their points of view. As Farrell and Héritier (2003: 588) describe, these 'trialogues' have become a normal practice, allowing officials to clarify and modify proposals.

We anticipate that different negotiation mechanisms may be at work in these different settings, with more member state influence in the early stages and more interplay between the Council and the European Parliament at the end. A comparison of four member states shows that the role of private interests and the agenda-setting ministries is particularly important, for example, while parliamentary actors are only rarely able to influence these domestic pre-negotiations (Schneider and Baltz 2005).

This view of EU policy-making is closer to that of the 'mixed models' in this volume, which combine a single preliminary round of negotiation or position exchanges with a subsequent procedural voting stage. However, in reality, there may be several preliminary rounds among different sets of actors, and there is no guarantee that the same norms and procedures apply to all. Further work will be needed to match the models more closely to the political facts. 
In this enterprise, the dataset used in this book should help improve the realism of future models. For example, Garrett and Tsebelis (200га) suggest modelling the conciliation committee negotiations between the Council and Parliament under co-decision as a bargaining game. In contrast, Napel and Widgrén (2004b) consider the internal decisionmaking rules in the Council and the European Parliament as a part of the bargaining model. This is done by assuming that bargaining in the conciliation committee is a two-person game between the pivotal players of the Council and Parliament. When the Nash bargaining solution is used as a solution concept in the model, the results suggest that QMV gives the Council a substantial bargaining advantage over the Parliament in the co-decision procedure. If unanimity is the norm in the Council, then Parliament is even more disadvantaged. Our data set makes possible straightforward empirical investigation of this theoretical result.

\section{I.5 THEORETICAL TOOLS FOR FUTURE RESEARCH \\ ON EU POLITICS}

In this study, the research teams focused on some mainstream rational choice models that have been developed for explaining EU politics. Other alternatives are of potential relevance to the study of legislative decisionmaking in the Union. One route is to analyse legislative decision-making under the assumptions of incomplete information, in which the Council members as well as the relevant groups within Parliament adapt their positions during the decision-making process to the yet unknown preferences of others. The experience gained in related situations with models of incomplete information is encouraging. Some studies are available, for instance, on how the Commission adapts to information problems (Broscheid and Coen 2003), on the selection of Commissioners and how they affect policy (Crombez 2002), and on the usage of threats in the deliberations of the European Council (Schneider and Cederman I994).

Although most legislative bargaining models have relied on cooperative game theory, there are some tools in non-cooperative game theory that could be exploited. One important recent contribution has been the $n$-actor models that Baron and Ferejohn (r989) and Merlo and Wilson (1995) have developed, and that are briefly discussed in the contribution by Bailer and Schneider. These models have also been applied to the question of government formation. It is possible to use these models to study coalition formation in a dynamic setting. 
The results of our study indicate that common interests and shared norms play a large role in the EU decision-making process. From a gametheoretic view, equilibria of that kind are customarily derived from dynamic models in which actors have an extended past and future in common. In the EU as in the models, reciprocal, non-negotiated exchanges create expectations among the actors that present concessions will be rewarded in the future, when their own interests are particularly at stake. Future models should explicitly incorporate the conditions under which norms are enforceable, and should adapt their predictions according to the condition that is applicable (Stokman 2004; 2005).

Another possible way forward is to add complexity to the goals actors pursue in the political process. Some rational choice models assume that actors aim not only at self-interested gain, but that hedonic and normative goals are also important (Lindenberg 200I). Normative goals in particular provide a way to avoid the complications of dynamic game theory and still explain why the unanimity norm seems so prevalent. According to March and Olsen (I989) relevant political actors sometimes refrain from exploiting their strategic advantage due to a 'logic of appropriateness'. Instead, they follow certain rules that prescribe the behaviour expected of them. These rules might very well yield predictions about outcomes that are located between the various points of view of the actors, somewhere in the 'centre' or the 'middle' of the political spectrum, as the cooperative bargaining models do. It is in such a context that Jacques Chirac could break the opposition of Cyprus against the December 2004 settlement regarding the beginning of talks with Turkey by saying: 'This is not the way we do business in the EU, mon cher Tassos'. ${ }^{4}$ The potential of such models has hardly been touched upon in EU research. ${ }^{5}$

Similarly, evolutionary game theory, which builds upon psychological theories of human behaviour and learning, may help limit the assumptions of excessive human rationality in current models (Weibull I995; Fudenberg and Levine 1998). Models with limitedly rational actors could highlight why decision-makers in the Council of Ministers often use cultural affiliation when they decide on where they obtain information (Beyers and Dierickx 1997). On the empirical side, future comparative evaluations of models could explore whether cultural factors or

${ }^{4}$ Information obtained from Dutch diplomats, as reported in the weekly Elsevier of 22 January 2005, p 23.

5 A partial exception is Kollman's (2003) computational model of the rotating presidency of the Council of Ministers. 
coalitional considerations affect the bargaining processes within the European Union.

\section{I.6 THE FUTURE OF THE EUROPEAN UNION}

This study indicates that the preferences of the member states still have considerable impact on the outcomes of legislative decision-making. At the same time, we have also found that knowing the member states' preferences alone is not enough. Forecasts improve when the Commission and Parliament are taken into account. A strictly defined intergovernmental perspective is therefore no longer helpful for understanding the day-to-day decision-making in the EU. The preferences of the Commission and Parliament matter. The daily decision-making in the Union can therefore be characterised as a mixture of intergovernmental and supranational bargaining.

These findings raise hope for the Union's long-term legitimacy. The strong emphasis on consensual decision-making and the involvement of Parliament indicate that outcomes reflect centrist European opinions. Admittedly, national positions and parliamentary preferences may not be identical with popular views. Nevertheless, the effective involvement of Parliament in the decision-making process strengthens the procedural legitimacy of the Union. In this respect, Europe is on the right track.

The substantive or 'social' legitimacy (Weiler I999: 80), that is, the general acceptance of the system of collective decision-making, is a different matter. The low turnout at European Parliament elections is revealing. Various proposals have been made to improve the Union's legitimacy, including more than transparent decision-making procedures, the avoidance of informal meetings in which compromises are made, and greater involvement by Parliament. Some of us in the research project believe these changes would be effective, while others are sceptical. What we are agreed on is that the Union needs greater acceptance of its decisions by the people of Europe.

The findings in this volume also bear on the enlargement process and the now-stalled European Constitution. The member states had great difficulty changing some of the procedural rules in the Treaty of Nice (200I) and in the recent negotiations over the European Constitution draft (2004). One of the main lessons of this project has been the importance of informal bargaining and compromise seeking. Applied to an EU of 25 or 27 members, the widely stated fear of paralysis is obvious if those members hold rather heterogeneous views and are not willing to 
compromise. Previous analyses indicate that the shape of future preference profiles of the various member states, including the new ones, is crucial in determining whether this happens (König and Bräuninger 2000; Steunenberg 200I; 2002b). For building the grand coalitions that promote consensus and accommodation of minorities, they argued that flexible and changing coalitions over time are important and that rigid factions must be avoided.

The EU enlargement from $\mathrm{I}_{5}$ to 25 member states increases the number of bilateral contacts from Io5 to 300 , which will make roundrobin consultations more difficult and grand coalitions more unwieldy. However, it is well to remember that previous enlargements with countries such as Spain and Portugal did not lead to substantial problems. Incidental blockades have always existed, including the British vetoes on all legislative proposals during the 'mad cow' crisis and the temporary attempt to exclude Austria from EU policy-making following the 'Haider' election. Furthermore, analyses of the Nice reform package, which was intended to prepare the Union for the 2004 enlargement, show that this package made the introduction of changes in existing EU policy more difficult and, in addition, preserves the power positions of the larger member states after enlargement (Steunenberg 2002b). Although the 2004 enlargement of the Union has put substantial stress on the Union's abilities to bring together different views, as Zimmer et al (2005) show, the member states recognised this and planned for it. The now defunct European Constitution, for example, proposed only marginal changes in the formal decision-making rules, in an effort to maintain the stability of day-to-day decision procedures.

The larger worry is not the formal rules but the informal norms. Common understandings are harder to enforce as groups grow in size. The erosion of shared norms in a larger Union may affect the Union's decision-making capability as enlargement proceeds. Only further analysis of the interdependency between the formal rules and the informal, day-to-day decision-making practices can confirm whether current fears concerning enlargement will materialise. The approaches developed in this book provide a starting point for this kind of analysis, and our findings point toward issues that need to be taken into account.

\section{II.7 CONCLUSION}

Will formal models of policy-making like those in this book ultimately become reliable aids to policy-makers? We do not share the pessimism of 
Rubinstein (2000: 74-75) who attributes no predictive power to game theory: 'I am not convinced that Game Theory is more valuable than a detective novel, a romantic poem, or a game of chess' in improving the strategic capabilities of practitioners. In particular, he points to the artificiality of some concepts, like mixed strategies, and notes that the usage of mathematical symbols 'creates an illusion of preciseness which does not have any basis in reality'. To the contrary, we all believe that our models can enlighten political debates, even when, as now, they have achieved only modest levels of predictive success.

Translating between the academic world and the policy world is never easy, however. Complicated models require explanation in plain language, with their limitations and imprecisions conveyed clearly to nonspecialists. Commercial opinion surveys have made much progress in this regard, and the best of them include in their reports information on their sample size, margin of error, and the response rates. Similarly, many evaluation associations impose a set of standards on their members who do practical research. We have tried to meet those standards throughout this book and particularly in Chapter Io, where our forecasting successes and limitations are described in detail.

The present volume has shown that a critical dialogue between different modelling traditions applied to a single data set forces researchers to make their modelling choices transparent, as honest science requires. It also makes the models vulnerable to empirical findings, a critical step in intellectual progress. Then, when models reach a certain stage of maturity and empirical success, reporting the results of such dialogues to policy-makers in accessible form seems to us part of the scholarly mission.

In short, we feel that this book itself proposes a model beyond those included in the individual chapters-a working model for collaborative social scientific research that aims at addressing issues of broad social interest and concern. In this project, we have engaged in a 'double dialogue' in which different theoretical claims encountered each other while each model faced a common data set. This kind of work is not easy, it is not cheap, and it imposes substantial administrative and managerial burdens on its practitioners. But when it is possible, both science and policy benefit. We are glad we did it.

But of course, the present book is just a beginning. We are confident that subsequent double dialogues will build on our findings, correct our errors, and continue to improve our common understanding of EU decision-making. 